\title{
Periacetabular Osteotomy Provides Higher Survivorship Than Rim Trimming for Acetabular Retroversion
}

\author{
Corinne A. Zurmühle MD, Helen Anwander MD, Christoph E. Albers MD, \\ Markus S. Hanke MD, Simon D. Steppacher MD, Klaus A. Siebenrock MD, \\ Moritz Tannast MD
}

Received: 16 May 2016/Accepted: 14 November 2016/Published online: 5 December 2016

(C) The Association of Bone and Joint Surgeons \& 2016

\begin{abstract}
Background Acetabular retroversion can cause impaction-type femoroacetabular impingement leading to hip pain and osteoarthritis. It can be treated by anteverting periacetabular osteotomy (PAO) or acetabular rim trimming with refixation of the labrum. There is increasing evidence that acetabular retroversion is a rotational abnormality of the entire hemipelvis and not a focal overgrowth of the anterior acetabular wall, which favors an anteverting PAO. However, it is unknown if this larger procedure would be beneficial in terms of survivorship and Merle d'Aubigné scores in a midterm followup compared with rim trimming.

Questions/purposes We asked if anteverting PAO results in increased survivorship of the hip compared with rim trimming through a surgical hip dislocation in patients with symptomatic acetabular retroversion.

Methods We performed a retrospective, comparative study evaluating the midterm survivorship of two matched patient groups with symptomatic acetabular retroversion undergoing either anteverting PAO or acetabular rim
\end{abstract}

One author (MT) has received funding from the Swiss National Science Foundation (SNSF).

All ICMJE Conflict of Interest Forms for authors and Clinical Orthopaedics and Related Research ${ }^{\circledR}$ editors and board members are on file with the publication and can be viewed on request. Each author certifies that his or her institution has approved the human protocol for this investigation and that all investigations were conducted in conformity with ethical principles of research.

C. A. Zurmühle, H. Anwander, C. E. Albers, M. S. Hanke,

S. D. Steppacher, K. A. Siebenrock, M. Tannast ( $\square)$

Department of Orthopaedic Surgery, Inselspital, Bern University

Hospital, University of Bern, Freiburgstrasse, 3010 Bern,

Switzerland

e-mail: moritz.tannast@insel.ch trimming through a surgical hip dislocation. Acetabular retroversion was defined by a concomitantly present positive crossover, posterior wall, and ischial spine sign. A total of 279 hips underwent a surgical intervention for acetabular retroversion at our center between 1997 and 2012 (166 periacetabular osteotomies, $113 \mathrm{rim}$ trimmings through surgical hip dislocation). A total of 99 patients $(60 \%)$ were excluded from the PAO group and 56 patients $(50 \%)$ from the rim trimming group because they had any of several prespecified conditions (eg, dysplasia or pediatric conditions 61 [37\%] for the PAO group and two [2\%] for the rim trimming group), matching (10 [6\%]/10 [9\%] hips), deficient records (10 [6\%]/13 [12\%] hips), or the patient declined or was lost to followup (18 [11\%]/31 [27\%] hips). This left 67 hips (57 patients) that underwent anteverting PAO and 57 hips (52 patients) that had acetabular rim trimming. The two groups did not differ in terms of age, sex, body mass index, preoperative ROM, preoperative Merle d'Aubigné-Postel score, radiographic morphology of the acetabulum (except total and anterior acetabular coverage), alpha angle, Tönnis grade of osteoarthritis, and labral and chondral lesions on the preoperative MRI. During the period in question, we generally performed PAO from 1997 to 2003. With the availability of surgical hip dislocation and labral refixation, we generally performed rim trimming from 2004 to 2010 . With growing knowledge of the underlying pathomorphology, anteverting PAOs became more common again around 2007 to 2008. A minimum followup of 2 years was required for this study. Failures were included at any time. The median followup for the anteverting PAO group was 9.5 years (range, 2-17.4 years) and 6.8 years (range, 2.2-10.5 years) for the rim trimming group $(\mathrm{p}<0.001)$. Kaplan-Meier survivorship analysis was performed using the following endpoints at 5 and 10 years: THA, radiographic 
progression of osteoarthritis by one Tönnis grade, and/or Merle d'Aubigné-Postel score $<15$ points.

Results Although the 5-year survivorship of the two groups was not different with the numbers available $(86 \%$ [95\% confidence interval $\{\mathrm{CI}\}, 76 \%-94 \%]$ for anteverting PAO versus $86 \%$ [95\% CI, 76\%-96\%] for acetabular rim trimming), we found increased survivorship at 10 years in hips undergoing anteverting PAO for acetabular retroversion (79\% [95\% CI, 68\%-90\%]) compared with acetabular rim trimming (23\% [95\% CI, 6\%-40\%]) at 10 years $(\mathrm{p}<$ 0.001 ). The drop in the survivorship curve for the acetabular rim trimming through surgical hip dislocation group started at Year 6. The main reason for failure was a decreased Merle d'Aubigné score.

Conclusions Anteverting PAO may be the more appropriate treatment for hips with substantial acetabular retroversion. This may be the result of reduction of an already smaller lunate surface of hips with acetabular retroversion through rim trimming. However, rim trimming may still benefit hips with acetabular retroversion in which only one or two of the three signs are positive. Future randomized studies should compare these treatments. Level of Evidence Level III, therapeutic study.

\section{Introduction}

Retroversion of the acetabulum is an accepted cause of impaction-type femoroacetabular impingement as a result of pincer-type pathomorphology [35], which reportedly is associated with hip pain and early osteoarthritis in young adults [9-11, 53]. The anterior overcoverage of the hip caused by the acetabular retroversion leads to early, painful osseous contact in hip flexion and internal rotation and subsequently to localized labrum and cartilage damage.

Acetabular retroversion was initially understood as a prominent overgrowth of the anterior acetabular wall [4], but there is increasing evidence that acetabular retroversion is a rotational abnormality of the entire hemipelvis $[15,16,28,36,44,49]$ rather than focal overgrowth.

In the last two decades, several approaches have been used to address anterior overcoverage. These have consisted of localized débridement or removal of the anterior acetabular rim via either open or arthroscopic techniques [29, 30, 33, 34, 43, 57] or by reorientation of the entire acetabulum by periacetabular osteotomy (PAO) resulting in anteversion $[31,39,40]$. At shortterm followup (defined as 2-4 years), both surgical treatments have demonstrated substantial improvements in clinical scores without radiographic progression of osteoarthritis [29-31, 33, 34, 39, 40, 43].

However, in the past several years, in our own practice, we noted that patients treated with anteverting PAO appeared to demonstrate superior results over the longer term to those treated with rim trimming. We posited that this observation supported the idea that rotational malalignment is the main source of acetabular retroversion, because the shape of the outer margin of the acetabular rim and the size of the lunate surface are essentially normal [23, 44].

Based on this background, we asked if anteverting PAO results in an increased cumulative 10-year survivorship of the hip compared with rim trimming through a surgical hip dislocation in a comparable group of patients with symptomatic acetabular retroversion (endpoints defined as a Merle d'Aubigné score of $<15$ points [6]; radiographic progression of osteoarthritis greater than one Tönnis grade [52]; and/or conversion to THA).

\section{Material and Methods}

We performed a retrospective, comparative study comparing the midterm survivorship of symptomatic hips with acetabular retroversion treated either with acetabular rim trimming or anteverting PAO. Based on our institutional database of surgical hip dislocations (1436 hips) and PAOs (520 hips) between 1997 and 2012 (Fig. 1), we identified all hips that had surgery for acetabular retroversion (279 hips) at our institution (Fig. 2). Acetabular retroversion was defined as a concomitantly present positive crossover sign of the anterior and posterior acetabular rim, a posterior wall sign, and ischial spine sign [16, 35].

During the period in question, the choice of surgical technique was based on the most recent understanding of the pathology and the availability of the surgical technique. The indication was consistently painfully restricted hip ROM in flexion and internal rotation with typical reproduction of groin pain. Before 2004, we generally treated acetabular retroversion by anteverting PAO (Fig. 2). Surgical hip dislocations have been performed since 1992 in our institution mainly for treatment of cam-type deformities [8]. Open rim trimming was introduced at the end of the 1990s. Labral refixation was introduced in 2001 and with growing experience and early success of rim trimming in less distinct acetabular retroversions, we applied this technique in hips with more pronounced acetabular retroversion with all three radiographic signs (crossover/posterior wall/ischial spine signs). This explains the decreased number of anteverting PAOs and the increased number of open acetabular rim trimmings around Year 2004 (Fig. 2). The number of surgical hip dislocations with rim trimming reached the maximum between 2004 and 2008. During this time, we learned that acetabular retroversion (defined as having all three signs) is a result of rotation of the hemipelvis $[8,15,16,44,49]$. In addition, the size of the lunate surface and the outer margin of the 
Fig. 1 The algorithm for our patient selection is shown. $\mathrm{LCE}=$ lateral center-edge.

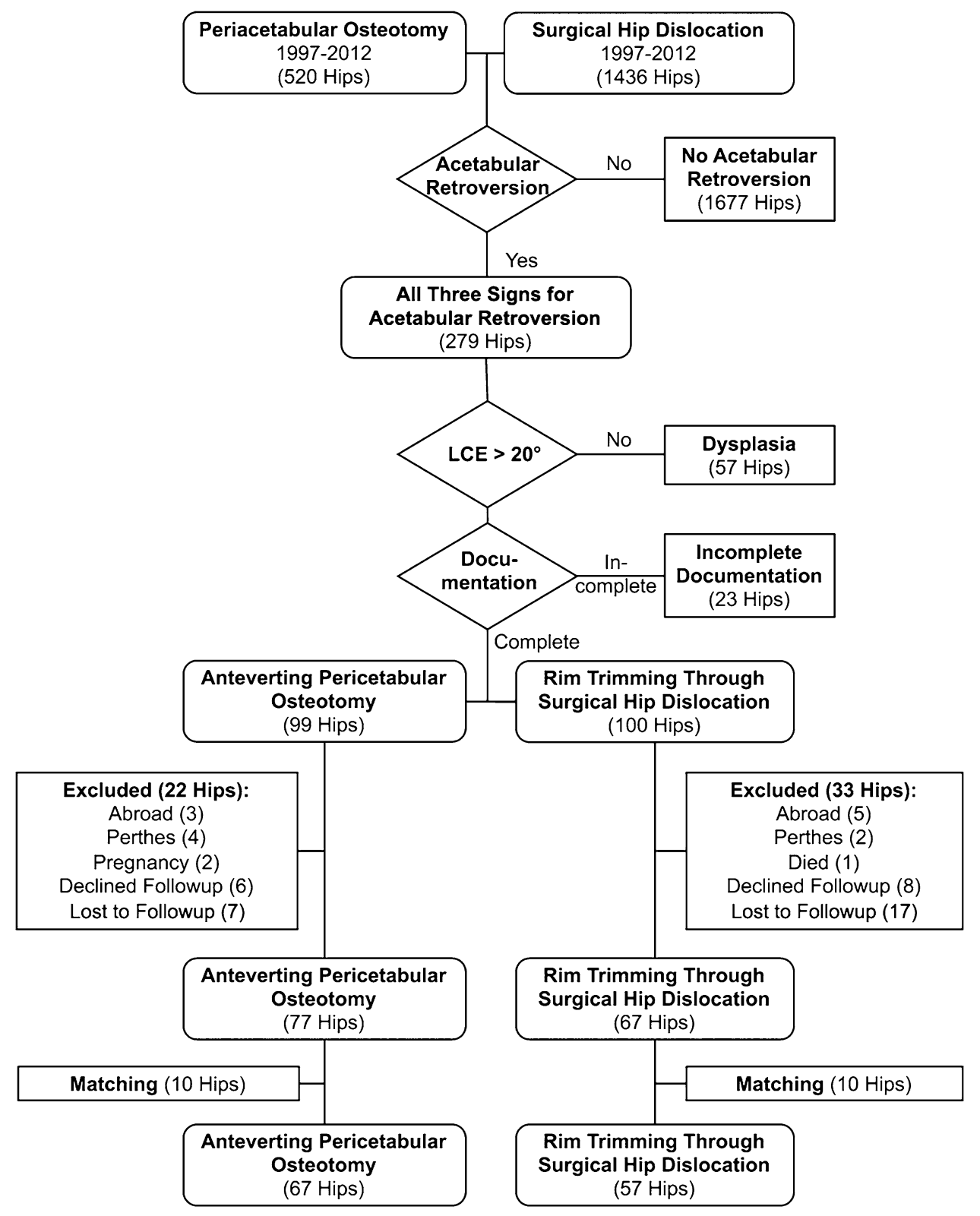

acetabular rim are normal in retroversion [44] and can theoretically be reduced in a critical way by rim trimming [3]. This explains the subsequent increased number of anteverting PAOs between 2007 and 2012 and is now our surgical treatment of choice for acetabular retroversion in most cases. During this transition time in Years 2007 to 2010, anteverting PAO was performed in younger patients, those younger than 35 years of age. Open acetabular rim trimming during this time period was indicated in patients older than 35 years of age with advanced anterosuperior cartilage damage, which would be rotated into the main weightbearing zone with anteverting PAO.

Because the use of the two surgical techniques was somewhat semisequential and overlapping resulting in different followup intervals, we sought to retrospectively look at all our procedures performed in our institution for acetabular retroversion, match the two groups, and finally compare the outcome with statistical methods that are specifically designed to account for variation in followup.

From those 279 hips treated for acetabular retroversion, we further excluded 57 hips with concomitant hip dysplasia (defined as a lateral center-edge angle of $<20^{\circ}$ [27, 53, 54]; Fig. 1) and hips with incomplete radiographic information (23 hips). Of the remaining 199 hips (99 hips with anteverting PAO and 100 hips with rim trimming), 22 hips with an anteverting PAO were further excluded as a result of the following reasons: living abroad (three hips), complex morphologic abnormalities (eg, Legg-Calvé-Perthes 
Fig. 2 The total number of patients undergoing PAO and surgical hip dislocation (SHD) and the number of patients included in this study between 1997 and 2012 are shown.
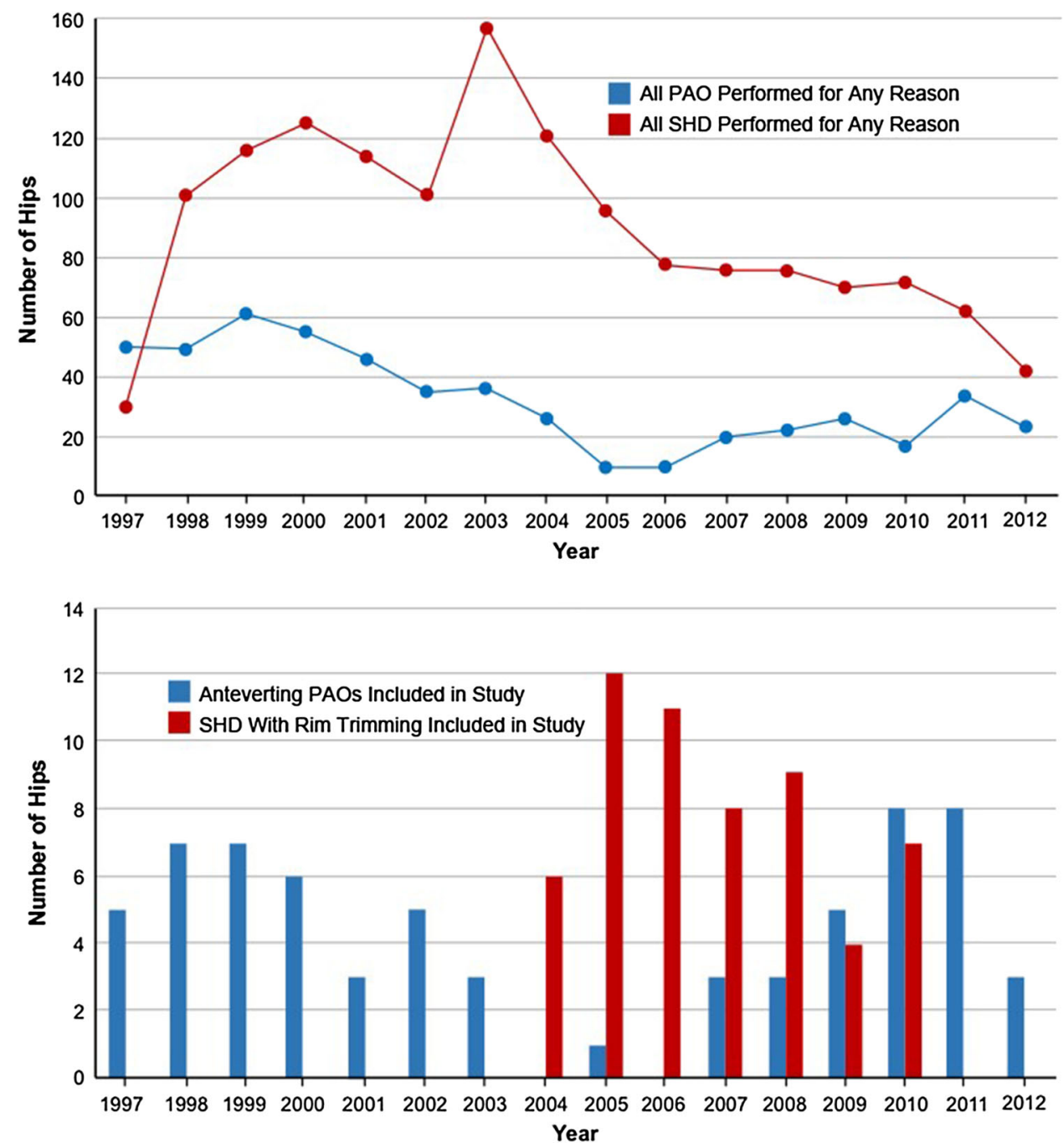

disease, four hips), pregnancy (two hips), routine followup declined (six hips), and lost to followup (seven hips). Of the remaining 100 hips with rim trimming, the following 33 hips were excluded: living abroad (five hips), complex morphologic deformities (eg, Legg-Calvé-Perthes disease, two hips), death unrelated to surgery (one hip), routine followup declined (eight hips), and lost to followup (17 hips). The remaining 77 anteverting PAOs and 67 hips with surgical rim trimming were comparable regarding demographics and preoperative radiography except for more men and older patients in the rim trimming through surgical hip dislocation group. To account for this difference, the two groups were matched as follows: all patients for both groups were sorted for age and sex with blinding of the followup. Stepwise exclusion of the youngest woman of the anteverting PAO group and of the oldest man of the rim trimming through surgical hip dislocation group was performed unless the differences in age and sex reached a $p$ value $>0.05$. This led to an exclusion of 20 hips (10 for each group), eventually resulting in two equivalent groups of 67 hips with anteverting PAO and 57 hips with acetabular rim trimming through a surgical hip dislocation (Fig. 1). Independent from the group allocation, the indication for surgery was painfully restricted hip ROM in flexion and internal rotation with typical reproduction of groin pain.

To demonstrate that the two groups were highly comparable, we assessed demographic parameters, pre- and postoperative clinical parameters, and pre- and postoperative radiographic parameters. Four preoperative demographic factors were assessed (age, sex, side, body mass index) and these did not differ between the two groups (Table 1).

Clinical parameters included the Merle d'Aubigné score [6], goniometric ROM (flexion/extension, internal/external rotation in $90^{\circ}$ of flexion, ab-/adduction), and the presence of a positive anterior impingement test (ie, painful internal rotation in $90^{\circ}$ of flexion), which were assessed by different observers because the study period covered more than one 
decade. We used the Merle d'Aubigné score [6], because this was the only consistently used clinical scoring system pre- and postoperatively. There were no differences between the two study groups for preoperative Merle d'Aubigné scores, clinical ROM of any amplitude, and the prevalence of a preoperative positive anterior impingement test (Table 1). The radiographic evaluation consisted of a preoperative and postoperative AP pelvic radiograph and a cross-table axial radiograph according to a standardized technique [50], which were available for all patients included in the final analysis. One observer (CAZ, not involved in the surgical care of the patients) assessed eight radiographic parameters preoperatively and postoperatively using previously developed and validated software, $\mathrm{Hip}^{2}$ Norm (University of Bern, Bern, Switzerland) [47, 51, 56]. Osteoarthritis was graded according to Tönnis [52], which reportedly has good inter- and intraobserver variability [45]. Preoperatively, the two groups did not differ in terms of preoperative radiographic Tönnis grade of osteoarthritis [52], lateral center-edge angle, acetabular index, extrusion index, posterior acetabular coverage, or alpha angle (Table 2). The anteverting PAO group had slightly higher preoperative total acetabular coverage and higher anterior acetabular coverage [46]. Postoperatively, all evaluated radiographic values were comparable except for the posterior acetabular coverage and the retroversion index. This difference resulted inherently as part of the surgical procedures, because anterior coverage is reduced with simultaneous increase of the posterior coverage in a reorienting osteotomy, whereas only anterior coverage is reduced in rim trimming. In addition, one of us (MSH, not involved in the surgical care of the patients) reviewed the preoperative MR images to objectively assess the preoperative joint degeneration. Only MRIs with intraarticular gadolinium contrast and a standardized technique including radial sequences were reviewed [22]. These were available for 37 of the 67 hips (55\%) of the anteverting PAO group and 48 of the 57 hips (84\%) of the rim trimming through surgical hip dislocation group. Lesions of the labrum and the acetabular/femoral cartilage were assessed and graded according to a previously published standardized grading system [38], which had moderate interobserver agreement for labral lesions and substantial agreement for lesions of the acetabular/femoral cartilage. There were no differences between the two groups for preoperative labral and/or acetabular/femoral cartilage lesions (Table 1).

Anteverting PAO was performed according to a previously described technique (Fig. 3A-B) [40, 41]. None of the 67 hips had refixation of the labrum. Thirty-four patients (51\% of the hips) underwent concomitant femoral osteochondroplasty through an anterior capsulotomy. Surgical hip dislocation with rim trimming was performed using a step-cut trochanteric osteotomy as described earlier
(Fig. 3C) [8]. In all 57 hips (100\%), labral refixation and femoral osteochondroplasty were performed. The rehabilitation protocol for both procedures consisted of early mobilization at postoperative Day 1, the use of continuous passive ROM, and partial weightbearing of 15 to $20 \mathrm{~kg}$ for 8 weeks for anteverting PAOs and $30 \mathrm{~kg}$ for 6 weeks for surgical hip dislocations.

Regardless of type of surgical treatment, patients were seen at 6 to 8 weeks, 3 months, 1 year, 2 years, and at 5year intervals thereafter or in cases of an unsatisfactory postoperative course at any time. A minimum followup of 2 years was required for this study. Failures were included at any time. The median followup for the anteverting PAO group was 9.5 years (mean $9.1 \pm 5.3$ years; range, $2-17.4$ years) and 6.8 years (mean $6.7 \pm 2.3$ years; range, $2.2-10.5$ years) for the rim trimming through surgical hip dislocation group $(\mathrm{p}<0.001)$.

We performed a power analysis for the primary research question regarding survivorship at 10 years followup with a two-sided level of significance of $5 \%$, beta error of $5 \%$, known long-term survivorship of hips undergoing anteverting PAO for acetabular retroversion of $71 \%$ with a SD of $17 \%$ [39], and known long-term survivorship of hips undergoing surgical hip dislocation of $80 \%$ for femoroacetabular impingement (FAI) with a SD of 5\% [42] resulting in a minimal sample size of at least 35 hips per group.

We tested normal distribution with the KolmogorovSmirnov test. Normally distributed data between the two study groups were compared using the unpaired t-test; data that were not normally distributed were compared using the Mann-Whitney U-test. Normally distributed data between the pre- and postoperative status were compared using the paired t-test; data that were not normally distributed were compared using the Wilcoxon rank-sum test. Fisher's exact test was used to compare binominal data among study groups. The survivorship was calculated using the method according to Kaplan and Meier [17] with the following endpoints: conversion to THA, radiographic progression of osteoarthritis greater than one grade according to Tönnis [52], and/or a Merle d'Aubigné-Postel score of $<15$ points (so-called fair or poor) [6]. The log-rank test was used to compare the two survivorship curves.

\section{Results}

At 5 years, rates of clinical failure were the same for the two patient groups $(86 \%$ [95\% confidence interval $\{\mathrm{CI}\}$, 76\%-94\%] for anteverting PAO versus $86 \%$ [95\% CI, $76 \%-96 \%$ ] for acetabular rim trimming). However, by 10 years, the patients treated with rim débridement fared worse with better survivorship at 10 years in hips undergoing anteverting PAO for acetabular retroversion $(79 \%$ 
Table 1. Demographic and radiographic data of the two study groups

\begin{tabular}{|c|c|c|c|}
\hline Parameter & Anteverting PAO & Surgical hip dislocation & $\mathrm{p}$ value \\
\hline Number of patients & 57 & 52 & - \\
\hline Number of hips & 67 & 57 & - \\
\hline Age (years) & $23 \pm 7(15-46)$ & $25 \pm 7(13-37)$ & 0.074 \\
\hline Gender (percent male of all hips) & 52 & 58 & 0.588 \\
\hline BMI $\left(\mathrm{kg} / \mathrm{m}^{2}\right)$ & $23 \pm 4(14-34)$ & $23 \pm 4(18-35)$ & 0.65 \\
\hline Side (percent right of all hips) & 47 & 60 & 0.209 \\
\hline Preoperative Merle d'Aubigné-Postel score [6] & $15 \pm 2(8-17)$ & $15 \pm 1(11-17)$ & 0.083 \\
\hline Pain & $3 \pm 1(1-5)$ & $4 \pm 1(2-5)$ & \\
\hline ROM & $6 \pm 1(5-6)$ & $5 \pm 1(2-6)$ & \\
\hline Walking ability & $6 \pm 1(4-6)$ & $6 \pm 1(4-6)$ & \\
\hline \multicolumn{4}{|l|}{ Preoperative ROM (degrees) } \\
\hline Flexion & $102 \pm 13(75-140)$ & $100 \pm 11(75-130)$ & 0.45 \\
\hline Extension & $4 \pm 5(0-20)$ & $1 \pm 3(0-10)$ & 0.06 \\
\hline Internal rotation & $16 \pm 13(-5$ to 45$)$ & $15 \pm 13(-10$ to 50$)$ & 0.554 \\
\hline External rotation & $37 \pm 16(5-70)$ & $34 \pm 13(0-16)$ & 0.814 \\
\hline Abduction & $42 \pm 11(20-70)$ & $36 \pm 12(20-60)$ & 0.073 \\
\hline Adduction & $27 \pm 10(10-50)$ & $24 \pm 13(10-50)$ & 0.609 \\
\hline \multicolumn{4}{|l|}{ Postoperative ROM (degrees) } \\
\hline Flexion & $101 \pm 9(85-130)$ & $105 \pm 10(70-120)$ & 0.003 \\
\hline Extension & $7 \pm 5(0-20)$ & $6 \pm 4(0-20)$ & 0.167 \\
\hline Internal rotation & $27 \pm 11(0-50)$ & $28 \pm 12(0-55)$ & 0.41 \\
\hline External rotation & $37 \pm 11(10-70)$ & $33 \pm 7(20-50)$ & 0.01 \\
\hline Abduction & $42 \pm 10(5-65)$ & $40 \pm 6(25-55)$ & 0.742 \\
\hline Adduction & $15 \pm 7(5-45)$ & $15 \pm 5(0-25)$ & 0.404 \\
\hline Postoperative impingement test (\% positive) & 28 & 39 & 0.076 \\
\hline \multicolumn{4}{|l|}{ Preoperative Tönnis osteoarthritis index [53] } \\
\hline Grade 0 & $65(97 \%)$ & $57(100 \%)$ & 0.188 \\
\hline Grade 1 & $2(2 \%)$ & $0(0 \%)$ & 0.188 \\
\hline Grade 2 & $0(0 \%)$ & $0(0 \%)$ & 1 \\
\hline Grade 3 & $0(0 \%)$ & $0(0 \%)$ & 1 \\
\hline \multicolumn{4}{|l|}{ Preoperative labral lesion on MRI [38] } \\
\hline Normal & $5(14 \%)$ & $9(19 \%)$ & 0.367 \\
\hline Intersubstance tear & $16(43 \%)$ & $26(54 \%)$ & 0.218 \\
\hline Intrasubstance tear & $0(0 \%)$ & $1(0 \%)$ & 0.57 \\
\hline Degeneration & $5(14 \%)$ & $4(8 \%)$ & 0.337 \\
\hline Inter- and intrasubstance & $10(10 \%)$ & $9(19 \%)$ & 0.258 \\
\hline \multicolumn{4}{|c|}{ Preoperative acetabular cartilage lesion on MRI [38] } \\
\hline Normal & $21(57 \%)$ & $27(58 \%)$ & 0.569 \\
\hline Thinning & $7(19 \%)$ & $7(15 \%)$ & 0.796 \\
\hline Delamination & $8(22 \%)$ & $12(25 \%)$ & 0.46 \\
\hline Defect & $1(0 \%)$ & $2(1 \%)$ & 0.598 \\
\hline \multicolumn{4}{|l|}{ Preoperative femoral cartilage lesion on MRI [38] } \\
\hline Normal & $37(100 \%)$ & $46(96 \%)$ & 0.316 \\
\hline Thinning & $0(0 \%)$ & $0(0 \%)$ & 1 \\
\hline Delamination & $0(0 \%)$ & $2(1 \%)^{*}$ & 0.316 \\
\hline Defect & $0(0 \%)$ & $0(0 \%)$ & 1 \\
\hline
\end{tabular}

Values are expressed as mean \pm SD with range in parentheses; *lesions between the 9 and 3 o'clock positions; MRI available for 37 hips of the anteverting PAO group and 48 hips of the rim trimming group; PAO = periacetabular osteotomy; $\mathrm{BMI}=$ body mass index. 
Table 2. Radiographic parameters of the two study groups pre- and postoperatively

\begin{tabular}{|c|c|c|c|c|c|c|c|c|c|}
\hline \multirow[t]{2}{*}{ Parameters } & \multirow{2}{*}{$\begin{array}{l}\text { Reference } \\
\text { values } \\
{[46]}\end{array}$} & \multicolumn{2}{|c|}{ Anteverting PAO } & \multicolumn{2}{|c|}{ Surgical hip dislocation } & \multirow{2}{*}{$\begin{array}{l}\mathrm{p} \\
\text { value* }^{*}\end{array}$} & \multirow{2}{*}{$\begin{array}{l}\mathrm{p} \\
\text { value }^{\dagger}\end{array}$} & \multirow{2}{*}{$\begin{array}{l}\mathrm{p} \\
\text { value* }\end{array}$} & \multirow{2}{*}{$\begin{array}{l}\mathrm{p} \\
\text { value }^{\S}\end{array}$} \\
\hline & & Preoperative & Postoperative & Preoperative & Postoperative & & & & \\
\hline Lateral center-edge angle $\left({ }^{\circ}\right)$ & $23-33$ & $33 \pm 8(18-56)$ & $36 \pm 8(14-62)$ & $34 \pm 5(23-46)$ & $29 \pm 7(15-55)$ & 0.486 & 0.247 & 0.539 & 0.613 \\
\hline Acetabular index $\left({ }^{\circ}\right)$ & $3-13$ & $3 \pm 7(-11$ to 16$)$ & $-1 \pm 7(-18$ to 16$)$ & $2 \pm 5(-12$ to 15$)$ & $5 \pm 6(-10$ to 17$)$ & 0.132 & 0.363 & 0.217 & 0.355 \\
\hline Extrusion index $\left(^{\circ}\right)$ & $17-27$ & $17 \pm 7(-4$ to 32$)$ & $16 \pm 7(-1$ to 37$)$ & $17 \pm 5(5-28)$ & $21 \pm 7(1-34)$ & 0.723 & 0.502 & 0.028 & 0.811 \\
\hline $\begin{array}{l}\text { Total acetabular coverage } \\
\text { (percent) }\end{array}$ & $70-83$ & $81 \pm 8(66-100)$ & $79 \pm 13(31-100)$ & $76 \pm 12(35-92)$ & $76 \pm 8(58-3)$ & 0.009 & 0.214 & 0.442 & 0.066 \\
\hline $\begin{array}{l}\text { Anterior acetabular coverage } \\
\text { (percent) }\end{array}$ & $15-26$ & $31 \pm 7(10-50)$ & $22 \pm 7(10-44)$ & $28 \pm 6(16-44)$ & $24 \pm 7(3-45)$ & 0.022 & 0.105 & 0.138 & 0.051 \\
\hline $\begin{array}{l}\text { Posterior acetabular coverage } \\
\text { (percent) }\end{array}$ & $36-47$ & $37 \pm 7(22-52)$ & $49 \pm 9(21-65)$ & $36 \pm 8(12-58)$ & $39 \pm 9(21-67)$ & 0.652 & 0.011 & 0.460 & $<0.001$ \\
\hline Alpha angle $[30]\left({ }^{\circ}\right)$ & $<50^{\circ}$ & $48 \pm 9(35-73)$ & $38 \pm 6(30-61)$ & $55 \pm 12(36-81)$ & $38 \pm 6(25-53)$ & 0.561 & 0.007 & $<0.001$ & 0.940 \\
\hline Retroversion index (\%) & 0 & $40 \pm 16(5-78)$ & $6 \pm 12(0-50)$ & $35 \pm 11(12-59)$ & $16 \pm 15(0-60)$ & 0.776 & 0.011 & 0.008 & 0.016 \\
\hline
\end{tabular}

Values are expressed as mean \pm SD with range in parentheses; *preoperative between the two groups; ${ }^{\dagger}$ preoperative versus postoperative for anteverting PAO; ${ }^{\ddagger}$ preoperative versus postoperative for surgical hip dislocation; ${ }^{\S}$ postoperative between the two groups; PAO = periacetabular osteotomy.

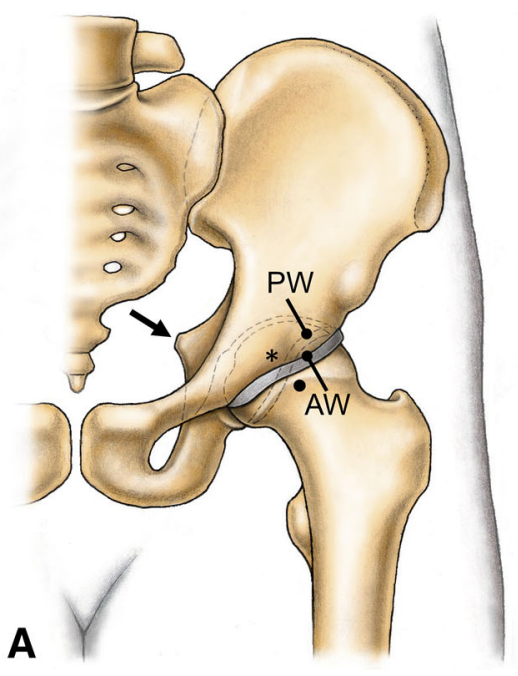

Fig. 3A-C (A) The definition of acetabular retroversion is illustrated. We defined acetabular retroversion as presence of all three following signs: a crossover sign (asterisk) of the anterior (AW) and posterior (PW) acetabular wall, a positive ischial spine sign (intrapelvinic protrusio of the ischial spine, arrow), and a positive posterior wall sign (the posterior wall runs medial to the femoral head

[95\% CI, 68\%-90\%]) compared with acetabular rim trimming $(23 \%$ [95\% CI, 6\%-40\%]) at 10 years $(\mathrm{p}<$ 0.001; Fig. 4). The substantial drop for the rim trimming through surgical hip dislocation group started 6 years postoperatively. Analyzing the failures in the first 10 years, hips undergoing acetabular rim trimming presented mainly with a higher prevalence of a Merle d'Aubigné-Postel score of $<15$ points $(\mathrm{p}=0.007$; Table 3 ), whereas we found no difference for the proportion that underwent conversion to THA ( $\mathrm{p}=0.908)$ or in radiographic progression of osteoarthritis $(\mathrm{p}=0.953)$.

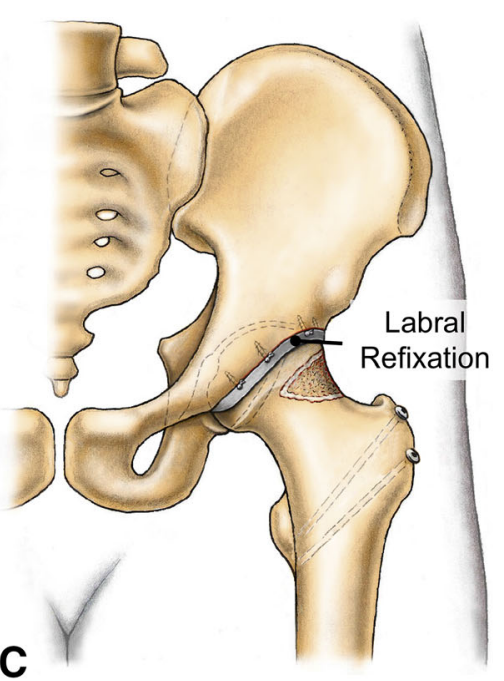

center). (B) The treatment with an anteverting PAO with optional concomitant femoral osteochondroplasty is shown. The labrum is typically not addressed. (C) The treatment by acetabular rim trimming with labral refixation through a surgical hip dislocation is shown. Two trochanteric screws are needed to refix the greater trochanteric osteotomy.

\section{Discussion}

Acetabular retroversion can cause impaction-type FAI leading to hip pain and osteoarthritis. It can be treated by anteverting PAO (Fig. 5A-C) [31, 40, 41, 48] or acetabular rim trimming $[2,7,13,29,42]$ with refixation of the labrum (Fig. 6A-C). In the past years, both techniques were in common use with similar short-term results. There is increasing evidence that acetabular retroversion is a rotational abnormality of the entire hemipelvis and not a focal overgrowth of the anterior acetabular wall, which would be 


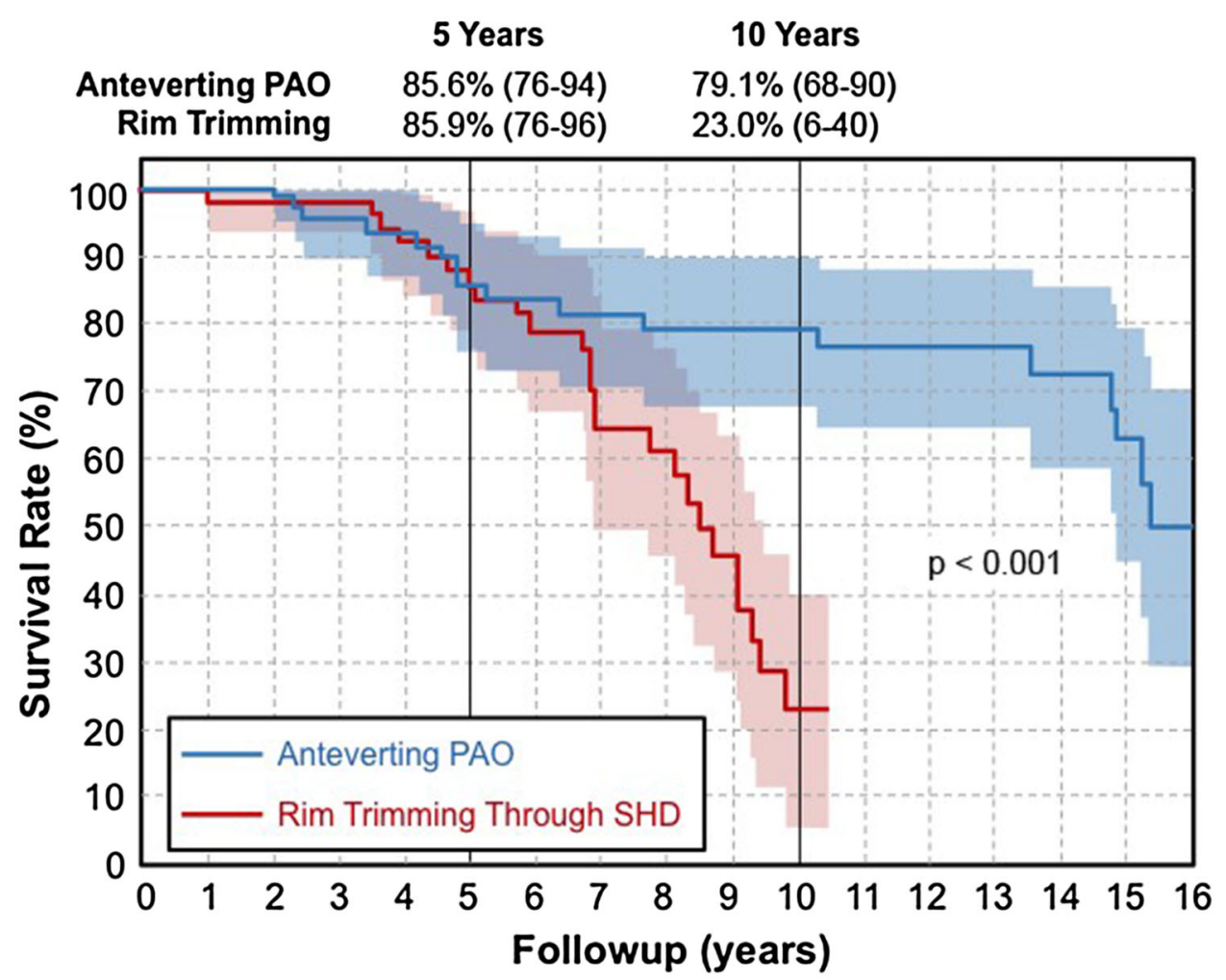

Fig. 4 This figure shows the Kaplan-Meier survivorship for anteverting PAO for symptomatic acetabular retroversion compared with rim trimming through a surgical hip dislocation (SHD). Endpoints were defined as: conversion to THA, radiographic progression of

Table 3. Reasons for failure for the two groups at 10 years

\begin{tabular}{lclc}
\hline Endpoint & $\begin{array}{l}\text { Anteverting } \\
\text { PAO } \\
(\mathrm{n}=67)\end{array}$ & $\begin{array}{l}\text { Rim trimming } \\
\text { through SHD } \\
(\mathrm{n}=57)\end{array}$ & $\mathrm{p}$ value \\
\hline THA & $1(1 \%)$ & $1(2 \%)$ & 0.908 \\
$\begin{array}{l}\text { Progression of } \\
\text { osteoarthritis* }\end{array}$ & $8(12 \%)$ & $7(12 \%)$ & 0.953 \\
$\begin{array}{c}\text { Merle d'Aubigné-Postel } \\
\text { score }<15 \text { points }\end{array}$ & $10(12 \%)$ & $18(32 \%)$ & 0.007 \\
\hline
\end{tabular}

*Hips undergoing THA were considered as having radiographic progression of osteoarthritis; values are given in absolute numbers with percentage in parentheses; $\mathrm{PAO}=$ periacetabular osteotomy; SHD $=$ surgical hip dislocation .

in favor of an anteverting PAO. However, it is unknown if this larger procedure would be beneficial in terms of survivorship and Merle d'Aubigné scores at midterm followup compared with rim trimming. We evaluated the midterm followup of two comparable groups of patients with symptomatic acetabular retroversion undergoing either anteverting PAO or rim trimming through a surgical hip dislocation. Patients with acetabular rim trimming had comparable survivorship at 5 years but this decreased osteoarthritis, and a Merle d'Aubigné-Postel score [6] of $<15$ points. Although there was comparable survivorship at 5 years, the survivorship curve for hips undergoing acetabular rim trimming dropped at 6 years compared with anteverting PAO $(\mathrm{p}=0.0002)$.

significantly after Year 6 (Fig. 4). The most commonly found reason for failure was a decreased Merle d'Aubigné score.

This study has limitations. First, our retrospective analysis does not imply a randomization of two procedures, which would be the ideal study design. The indication for either treatment has changed over time, which resulted in a semisequential series of two treatments. We note, however, that there were no clear, consistent indications for use of these procedures during the entire study period; rather, our surgical decision-making changed with time as we gained experience and understanding of acetabular pathology. These changes included the unavailability of the surgical technique of hip dislocation with trimming and labral refixation before 2004 and the improved scientific understanding of the underlying pathomorphology in acetabular retroversion around Years 2007 and 2012, which finally resulted in our chronologic distribution of these two surgeries in our department (Fig. 2). However, to account for our concerns for selection bias, we pooled all available patients from our institutional database with acetabular retroversion and checked for differences in demographics and preoperative morphology. Because the two groups 

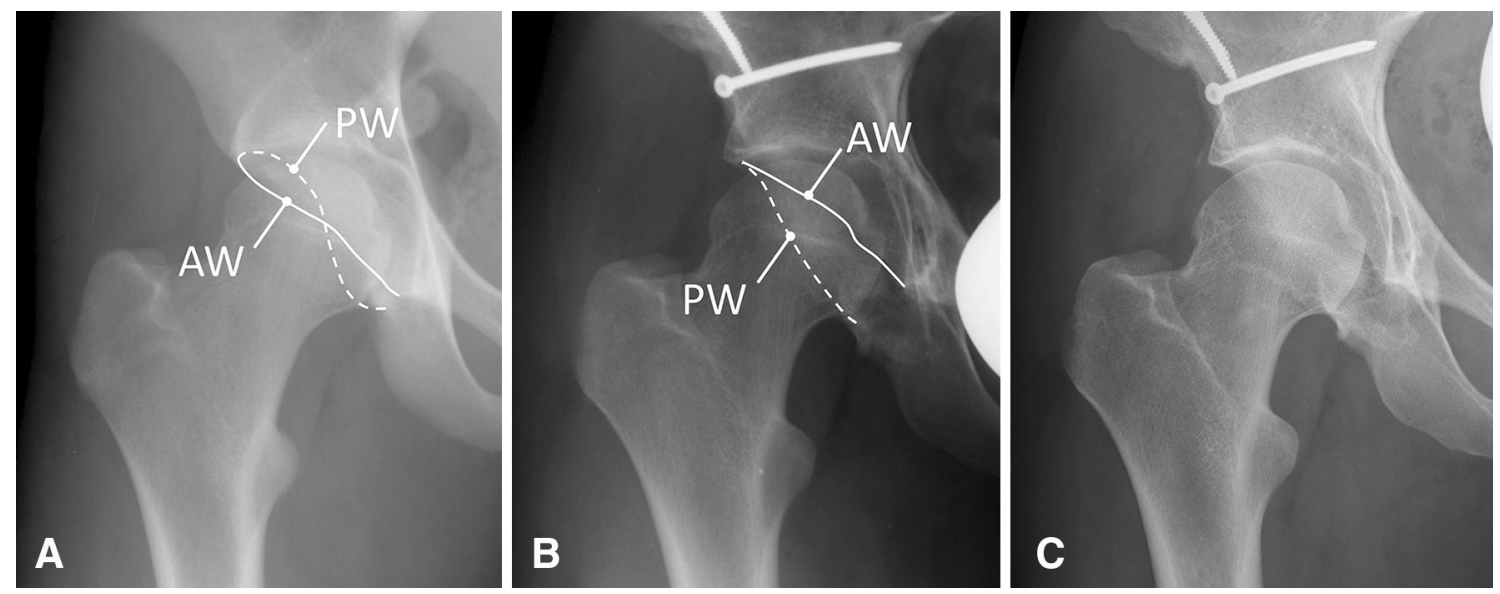

Fig. 5A-C An illustrative case of a 17-year-old patient with symptomatic acetabular retroversion is shown. (A) The preoperative image shows a positive crossover sign, a positive ischial spine sign, and a positive posterior wall sign. (B) The patient underwent anteverting PAO without radiographic signs of osteoarthritis at a 1-year $(\mathbf{B})$ and 12-year followup $(\mathbf{C})$. AW = anterior wall; $\mathrm{PW}=$ posterior wall.
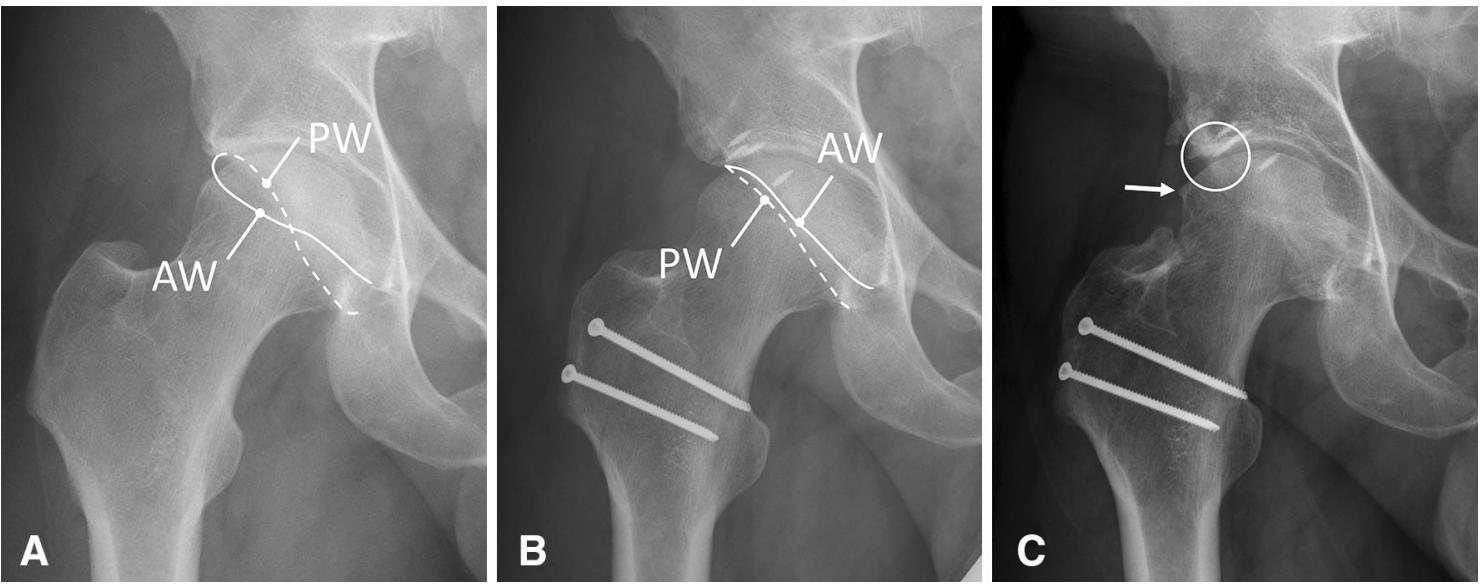

Fig. 6A-C An illustrative case of a 37-year-old patient with symptomatic acetabular retroversion is shown. (A) The preoperative morphology is very similar to the patient in Figure 5. All three signs for acetabular retroversion are positive. (B) The 1-year followup was

differed in terms of sex and age, we finally matched the two groups of surgical treatment blinded to their followup by stepwise exclusion until differences in age and sex reached a $p$ value $<0.05$. This resulted in two highly comparable groups of patients regarding demographics, preoperative ROM, preoperative Merle d'Aubigné scores, amount of preoperative articular damage based on MRI, preoperative radiographic acetabular and femoral morphology, and accuracy of postoperative correction underlying the validity of our results. Thus, we are confident that our findings are warranted. Second, we only analyzed retroverted hips in which all three signs for retroversion were concomitantly positive (crossover sign, posterior wall sign, ischial spine sign). We did not include favorable without signs of osteoarthritis. (C) However, the patient developed joint-space narrowing (circle) and osteophyte formation (arrow) at followup of 7 years indicating early OA. AW = anterior wall; $\mathrm{PW}=$ posterior wall.

patients presenting with only one or two of three criteria. Thus, this is a selected group, even within our own practice. Our conclusions are not generalizable for hips in which only a minor cranial crossover sign with a retroversion index of $<30 \%$ is present [39]. We therefore caution that our findings may not be applicable in other practice settings or in less severely affected hips. Third, we used the Merle d'Aubigné-Postel score [6] as the only patient-reported outcome measure. We are aware that there are more appropriate clinical scores available for young patients with FAI [24]. However, most of these new scores have been developed and validated in the past few years and were therefore not available for all our patients from 1997 preoperatively. Unlike other patient-reported 


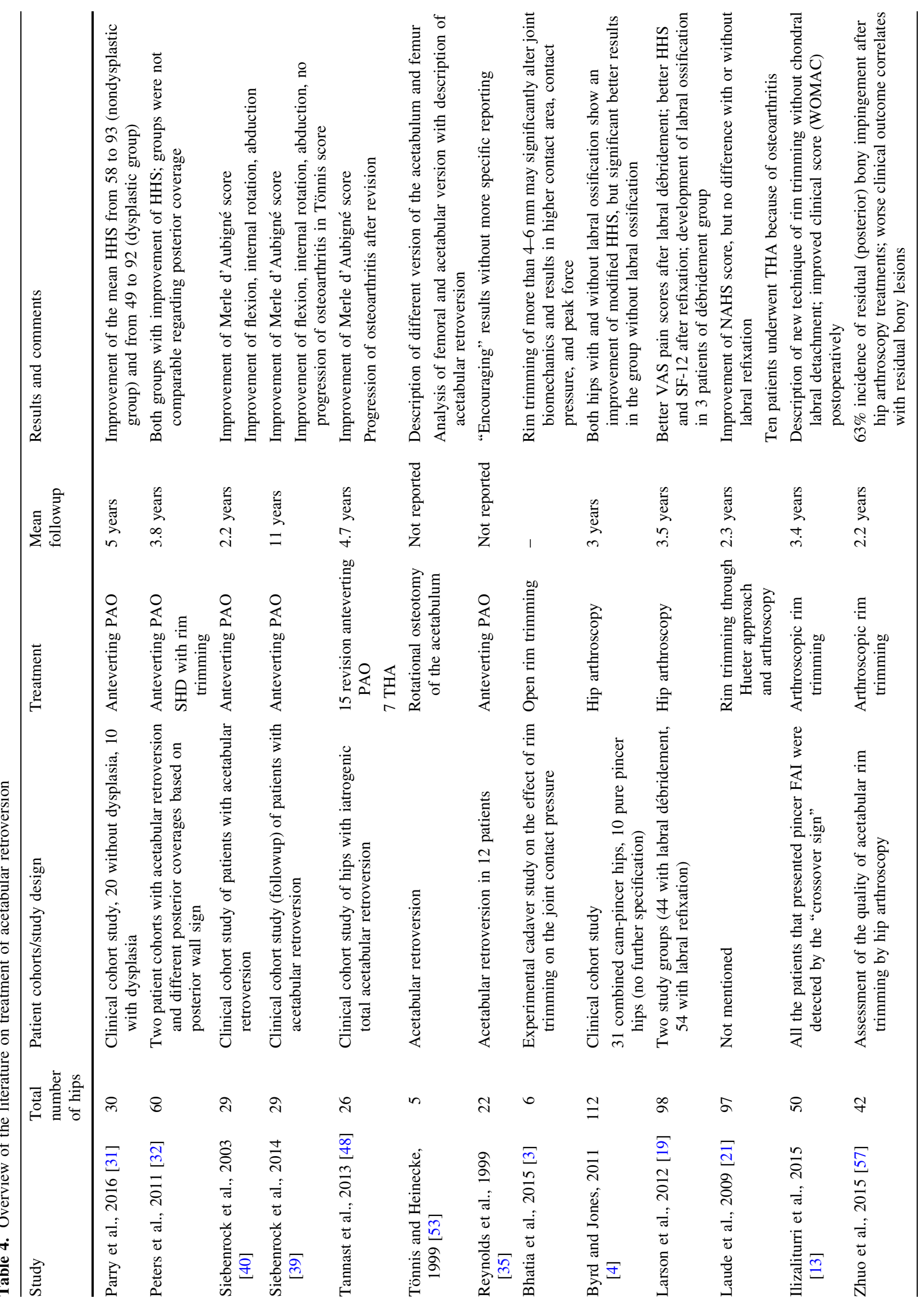


outcome measures, the Merle d'Aubigné score was available for all our patients at any followup. We also note that blinding of observers after surgery was not possible because the routine clinical followup evaluation included an assessment of the surgical scar, which inherently would have revealed the type of surgical procedure. Nevertheless, excellent inter- and intraobserver agreement has been reported for the Merle d'Aubigné-Postel score [6] as well as for the assessment of the clinical ROM and the anterior impingement test $[25,26,55]$. Fourth, we do not have standard preoperative MRI for all patients included in the study mostly because patients already presented with an MRI from another institution or the MRIs were no longer retrievable. However, because the demographic and conventional radiographic data of patients with and without MRI were comparable, this should not jeopardize our results. Fifth, the mean followup interval for the rim trimming through surgical dislocation group is smaller. However, this is accounted for statistically by the log-rank test. This test is a time-stratified test that was specifically designed to analyze potential differences of two survivorship curves with different followup intervals. In addition, the shorter followup interval would be in favor of the surgical dislocation group. Inevitably for a study period spanning 15 years, different observers assessed these parameters preoperatively. However, substantial inter- and intraobserver agreement has been reported previously for ROM [12, 26, 55] and the anterior impingement test [25]. Sixth, we have a different rate of patients who either declined routine followup or were lost to followup for the two groups (13\% for the anteverting PAO group versus $25 \%$ for the rim trimming through surgical hip dislocation group). Because patients lost to followup usually present with similar [5, 18] or worse [14] results, this would strengthen our conclusion that rim trimming for symptomatic acetabular retroversion results in less favorable results compared with anteverting PAO.

Comparing our midterm failure rates with those of others (Table 4), consistently good results have been reported for the anteverting PAO procedure in acetabular retroversion. A direct comparison of the survivorship curves is difficult because various endpoints beyond THA have been used (Table 4). Reports of isolated open or arthroscopic acetabular rim trimming for acetabular retroversion are not available with a followup of 10 years. Most of the reports have a followup of $<5$ years $[4,19,33]$ or report on "pincer"-type hips without further specification $[1,29,42]$. There is only one study comparing the surgical treatments for acetabular retroversion. In this study, Peters et al. [32] differentiated between the two surgical treatments analyzing two different morphologic types of acetabular retroversion: one with a deficient posterior wall and one with sufficient posterior coverage. The followup 
after 4 years was comparable regarding the Harris hip score. However, these results have to be considered preliminary because, based on our results, the potential drop in the survivorship curve occurs at Year 6. Our results should be considered as pilot results that offer valuable information to conduct future prospective randomized trials comparing both surgical treatments for acetabular retroversion. We hypothesize that the better outcomes seen with reorientation osteotomy compared with rim trimming occur because the underlying pathology represents a global rotational abnormality of the entire hemipelvis rather than focal overgrowth of the rim $[15,16,23,44,49]$. When looking at the surgical treatment of our patient cohort, this is particularly interesting for two reasons. First, none of the patients undergoing anteverting PAO had surgical treatment of the labrum, whereas all patients undergoing surgical hip dislocation underwent labral refixation. Obviously, despite the reported importance of labral refixation [7, 19-21, 37], the patients appear to benefit more from correct acetabular orientation. Second, although the preoperative asphericity of the femoral head-neck junction was comparable in the two groups (Table 2), osteochondroplasty of the femoral head-neck junction was performed less frequently in the anteverting PAO group. Again, this would favor the surgical dislocation group in which asphericity was corrected in all cases.

In summary, anteverting PAO seems the more appropriate treatment of acetabular retroversion (defined by concomitantly present crossover/ischial spine/posterior wall signs) because symptomatic acetabular retroversion can be treated efficiently without compromising the already small lunate surface area in these hips. Our results are not valid for hips that present with a crossover sign only. Based on the data from others [32], acetabular rim trimming may be a valid option for treatment of hips with a positive crossover sign but concomitantly sufficient posterior coverage.

Acknowledgments We thank Florian Schmaranzer, MD, for his help in the evaluation of the MRIs. Funding was provided by the Swiss National Science Foundation (SNSF).

\section{References}

1. Beaulé PE, Le Duff MJ, Zaragoza E. Quality of life following femoral head-neck osteochondroplasty for femoroacetabular impingement. J Bone Joint Surg Am. 2007;89:773-779.

2. Beck M, Leunig M, Parvizi J, Boutier V, Wyss D, Ganz R. Anterior femoroacetabular impingement: part II. Midterm results of surgical treatment. Clin Orthop Relat Res. 2004;418:67-73.

3. Bhatia S, Lee S, Shewman E, Mather RC, Salata MJ, BushJoseph CA, Nho SJ. Effects of acetabular rim trimming on hip joint contact pressures: how much is too much? Am J Sports Med. 2015;43:2138-2145.
4. Byrd JWT, Jones KS. Arthroscopic management of femoroacetabular impingement in athletes. Am $J$ Sports Med. 2011;39(Suppl):7S-13S.

5. Choi JK, Geller JA, Patrick DA, Wang W, Macaulay W. How are those 'lost to follow-up' patients really doing? A compliance comparison in arthroplasty patients. World $J$ Orthop. 2015;6:150-155.

6. D'Aubigne RM, Postel M. Functional results of hip arthroplasty with acrylic prosthesis. J Bone Joint Surg Am. 1954;36:451-475.

7. Espinosa N, Rothenfluh D, Beck M, Ganz R, Leunig M. Treatment of femoro-acetabular impingement: preliminary results of labral refixation. J Bone Joint Surg Am. 2006;88:925-935.

8. Ganz R, Gill TJ, Gautier E, Ganz K, Krügel N, Berlemann U. Surgical dislocation of the adult hip a technique with full access to the femoral head and acetabulum without the risk of avascular necrosis. J Bone Joint Surg Br. 2001;83:1119-1124.

9. Giori NJ, Trousdale RT. Acetabular retroversion is associated with osteoarthritis of the hip. Clin Orthop Relat Res. 2003;417:263-269.

10. Harris WH. Traumatic arthritis of the hip after dislocation and acetabular fractures: treatment by mold arthroplasty. An end-result study using a new method of result evaluation. J Bone Joint Surg Am. 1969;51:737-755.

11. Harris WH. Etiology of osteoarthritis of the hip. Clin Orthop Relat Res. 1986;213:20-33.

12. Holm I, Bolstad B, Lütken T, Ervik A, Røkkum M, Steen H. Reliability of goniometric measurements and visual estimates of hip ROM in patients with osteoarthrosis. Physiother Res Int. 2000;5:241-248.

13. Ilizaliturri VM, Joachin P, Acuna M. Description and mid-term results of the 'over the top' technique for the treatment of the pincer deformity in femoroacetabular impingement. J Hip Preserv Surg. 2015;2:369-373.

14. Jones WB, Taylor SM, Kalbaugh CA, Joels CS, Blackhurst DW, Langan EM, Gray BH, Youkey JR. Lost to follow-up: a potential under-appreciated limitation of endovascular aneurysm repair. $J$ Vasc Surg. 2007;46:434-440; discussion 440-441.

15. Kakaty DK, Fischer AF, Hosalkar HS, Siebenrock KA, Tannast M. The ischial spine sign: does pelvic tilt and rotation matter? Clin Orthop Relat Res. 2010;468:769.

16. Kalberer F, Sierra RJ, Madan SS, Ganz R, Leunig M. Ischial spine projection into the pelvis: a new sign for acetabular retroversion. Clin Orthop Relat Res. 2008;466:677-683.

17. Kaplan EL, Meier P. Nonparametric estimation from incomplete observations. J Am Stat Assoc. 1958;53:457.

18. King PJ, Malin AS, Scott RD, Thornhill TS. The fate of patients not returning for follow-up five years after total knee arthroplasty. J Bone Joint Surg Am. 2004;86:897-901.

19. Larson CM, Giveans MR, Stone RM. Arthroscopic débridement versus refixation of the acetabular labrum associated with femoroacetabular impingement: mean 3.5-year follow-up. Am J Sports Med. 2012;40:1015-1021.

20. Laude F, Sariali E. Treatment of FAI via a minimally invasive ventral approach with arthroscopic assistance. Technique and midterm results. Orthopade. 2009;38:419-428.

21. Laude F, Sariali E, Nogier A. Femoroacetabular impingement treatment using arthroscopy and anterior approach. Clin Orthop Relat Res. 2009;467:747-752.

22. Leunig M, Werlen S, Ungersböck A, Ito K, Ganz R. Evaluation of the acetabular labrum by MR arthrography. J Bone Joint Surg Br. 1997;79:230-234.

23. Liechti EF, Ferguson SJ, Tannast M. Protrusio acetabuli: joint loading with severe pincer impingement and its theoretical implications for surgical therapy. J Orthop Res. 2015;33:106113. 
24. Lodhia P, Slobogean GP, Noonan VK, Gilbart MK. Patient-reported outcome instruments for femoroacetabular impingement and hip labral pathology: a systematic review of the clinimetric evidence. Arthroscopy. 2011;27:279-286.

25. Martin RL, Sekiya JK. The interrater reliability of 4 clinical tests used to assess individuals with musculoskeletal hip pain. $J$ Orthop Sports Phys Ther. 2008;38:71-77.

26. McWhirk LB, Glanzman AM. Within-session inter-rater reliability of goniometric measures in patients with spastic cerebral palsy. Pediatr Phys Ther. 2006;18:262-265.

27. Murphy SB, Ganz R, Müller ME. The prognosis in untreated dysplasia of the hip. A study of radiographic factors that predict the outcome. J Bone Joint Surg Am. 1995;77:985-989.

28. Murphy SB, Kijewski PK, Millis MB, Harless A. Acetabular dysplasia in the adolescent and young adult. Clin Orthop Relat Res. 1990;261:214-223.

29. Naal FD, Miozzari HH, Schär M, Hesper T, Nötzli HP. Midterm results of surgical hip dislocation for the treatment of femoroacetabular impingement. Am J Sports Med. 2012;40:1501-1510.

30. Palmer DH, Ganesh V, Comfort T, Tatman P. Midterm outcomes in patients with cam femoroacetabular impingement treated arthroscopically. Arthroscopy. 2012;28:1671-1681.

31. Parry JA, Swann RP, Erickson JA, Peters CL, Trousdale RT, Sierra RJ. Midterm outcomes of reverse (anteverting) periacetabular osteotomy in patients with hip impingement secondary to acetabular retroversion. Am J Sports Med. 2016;44:672-676.

32. Peters CL, Anderson LA, Erickson JA, Anderson AE, Weiss JA. An algorithmic approach to surgical decision making in acetabular retroversion. Orthopedics. 2011;34:10.

33. Peters CL, Schabel K, Anderson L, Erickson J. Open treatment of femoroacetabular impingement is associated with clinical improvement and low complication rate at short-term followup. Clin Orthop Relat Res. 2010;468:504-510.

34. Philippon MJ, Briggs KK, Yen YM, Kuppersmith DA. Outcomes following hip arthroscopy for femoroacetabular impingement with associated chondrolabral dysfunction: minimum two-year follow-up. J Bone Joint Surg Br. 2009;91:16-23.

35. Reynolds D, Lucas J, Klaue K. Retroversion of the acetabulum. A cause of hip pain. J Bone Joint Surg Br. 1999;81:281-288.

36. Sankar WN, Schoenecker J, Mayfield ME, Kim YJ, Millis MB. Acetabular retroversion in Down syndrome. J Pediatr Orthop. 2012;32:277-281.

37. Schilders E, Dimitrakopoulou A, Bismil Q, Marchant P, Cooke C. Arthroscopic treatment of labral tears in femoroacetabular impingement: a comparative study of refixation and resection with a minimum two-year follow-up. $J$ Bone Joint Surg Br. 2011;93:1027-1032.

38. Schmaranzer F, Klauser A, Kogler M, Henninger B, Forstner T, Reichkendler M, Schmaranzer E. Diagnostic performance of direct traction MR arthrography of the hip: detection of chondral and labral lesions with arthroscopic comparison. Eur Radiol. 2015;25:1721-1730.

39. Siebenrock KA, Schaller C, Tannast M, Keel M, Büchler L. Anteverting periacetabular osteotomy for symptomatic acetabular retroversion: results at ten years. J Bone Joint Surg Am. 2014;96:1785-1792.

40. Siebenrock KA, Schoeniger R, Ganz R. Anterior femoro-acetabular impingement due to acetabular retroversion. Treatment with periacetabular osteotomy. $J$ Bone Joint Surg Am. 2003;85:278-286.

41. Siebenrock KA, Steppacher SD, Tannast M, Büchler L. Anteverting periacetabular osteotomy for acetabular retroversion. JBJS Essential Surgical Techniques. 2015;5:e1.
42. Steppacher SD, Anwander H, Zurmühle CA, Tannast M, Siebenrock KA. Eighty percent of patients with surgical hip dislocation for femoroacetabular impingement have a good clinical result without osteoarthritis progression at 10 years. Clin Orthop Relat Res. 2015;473:1333-1341.

43. Steppacher SD, Huemmer C, Schwab JM, Tannast M, Siebenrock KA. Surgical hip dislocation for treatment of femoroacetabular impingement: factors predicting 5-year survivorship. Clin Orthop Relat Res. 2014;472:337-348.

44. Steppacher SD, Lerch TD, Gharanizadeh K, Liechti EF, Werlen SF, Puls M, Tannast M, Siebenrock KA. Size and shape of the lunate surface in different types of pincer impingement: theoretical implications for surgical therapy. Osteoarthritis Cartilage. 2014;22:951-958.

45. Steppacher SD, Tannast M, Ganz R, Siebenrock KA. Mean 20year followup of Bernese periacetabular osteotomy. Clin Orthop Relat Res. 2008;466:1633-1644.

46. Tannast M, Hanke MS, Zheng G, Steppacher SD, Siebenrock KA. What are the radiographic reference values for acetabular underand overcoverage? Clin Orthop Relat Res. 2015;473:1234-1246.

47. Tannast M, Mistry S, Steppacher SD, Reichenbach S, Langlotz F, Siebenrock KA, Zheng G. Radiographic analysis of femoroacetabular impingement with Hip2Norm-reliable and validated. $J$ Orthop Res. 2008;26:1199-1205.

48. Tannast M, Pfander G, Steppacher SD, Mast JW, Ganz R. Total acetabular retroversion following pelvic osteotomy: presentation, management, and outcome. Hip Int. 2013;23(Suppl 9):S14-26.

49. Tannast M, Pfannebecker P, Schwab JM, Albers CE, Siebenrock KA, Büchler L. Pelvic morphology differs in rotation and obliquity between developmental dysplasia of the hip and retroversion. Clin Orthop Relat Res. 2012;470:3297-3305.

50. Tannast M, Siebenrock KA, Anderson SE. Femoroacetabular impingement: radiographic diagnosis-what the radiologist should know. AJR Am J Roentgenol. 2007;188:1540-1552.

51. Tannast M, Zheng G, Anderegg C, Burckhardt K, Langlotz F, Ganz R, Siebenrock KA. Tilt and rotation correction of acetabular version on pelvic radiographs. Clin Orthop Relat Res. 2005;438:182-190.

52. Tönnis D. Congenital Dysplasia and Dislocation of the Hip in Children and Adults. Berlin, Heidelberg, Germany: Springer; 1987. Available at: http://link.springer.com/10.1007/978-3-64271038-4. Accessed May 10, 2016.

53. Tönnis D, Heinecke A. Acetabular and femoral anteversion: relationship with osteoarthritis of the hip. J Bone Joint Surg Am. 1999;81:1747-1770.

54. Wiberg G. The anatomy and roentgenographic appearance of a normal hip joint. Acta Orthop Scand. 1939;83(Suppl 58):7-38.

55. Wyss TF, Clark JM, Weishaupt D, Nötzli HP. Correlation between internal rotation and bony anatomy in the hip. Clin Orthop Relat Res. 2007;460:152-158.

56. Zheng G, Tannast M, Anderegg C, Siebenrock KA, Langlotz F. Hip2Norm: an object-oriented cross-platform program for 3D analysis of hip joint morphology using 2D pelvic radiographs. Comput Methods Programs Biomed. 2007;87:36-45.

57. Zhuo H, Wang X, Liu X, Song GY, Li Y, Feng H. Quantitative evaluation of residual bony impingement lesions after arthroscopic treatment for isolated pincer-type femoroacetabular impingement using three-dimensional CT. Arch Orthop Trauma Surg. 2015;135:1123-1130. 